\title{
Factors Influencing the Utilization of Physiotherapy Services Among the Children with Cerebral Palsy at Protibondhi Seba-O-Sahajjo Kendro in Bangladesh
}

\author{
Md. Rafiqul Islam ${ }^{1}$, Ershad Ali $^{2}$, Rasel Howlader ${ }^{3}$ \\ ${ }^{1}$ Protibondhi Seba-O-Sahajjo Kendro (PSOSK), Jatiyo Protibondhi Unnayan Foundation (JPUF), Ministry of Social Welfare, Dhaka, \\ Bangladesh \\ ${ }^{2}$ Walk for Life - The Clubfoot Program of Bangladesh, Dhaka, Bangladesh \\ ${ }^{3}$ BRAC Education Program (BEP), Dhaka, Bangladesh
}

Email address

rafiqulphysio@gmail.com (R. Islam),physioershad@gmail.com (E. Ali), howlader.rasel@yahoo.com (R. Howlader)

\section{To cite this article:}

Md. Rafiqul Islam, Ershad Ali, Rasel Howlader. Factors Influencing the Utilization of Physiotherapy Services Among the Children with Cerebral Palsy at Protibondhi Seba-O-Sahajjo Kendro in Bangladesh. International Journal of Neurologic Physical Therapy.

Vol. 7, No. 1, 2021, pp. 1-6. doi: 10.11648/j.ijnpt.20210701.11

Received: March 8, 2021; Accepted: March 27, 2021; Published: April 30, 2021

\begin{abstract}
Background: Cerebral palsy (CP) is a non-progressive irreversible lesion either single or multiple areas of the immature brain due to a developmental abnormality of brain or injury of the brain during labor, at the time of birth or during delivery. The prevalence of cerebral palsy is $2.5 \%$ per one thousand live births. Children with cerebral palsy required rehabilitation care both at home and rehabilitation center. The study aims to find out the factors affecting adherence to physiotherapy appointment for caregivers of children with cerebral palsy in Bangladesh. Methods: A cross-sectional study designed to conduct the research a total of 225 cerebral palsy child from the 14 Protibondhi Seba-O-Sahajjo Kendro (PSOSK) at the different district of the Bangladesh were selected through random sampling techniques by face-to-face interviews. This data collection procedure was completed within one month. Chi square test were used for statistical analysis of data and the significant level set at $\mathrm{p}<0.05$. Results: Study shows that among the $225 \mathrm{CP}$ child only $33.8 \%$ maintain adherence and $66.2 \%$ was non-adherence. Different variables such as numbers of siblings, doctors' consultation, parents' level of education and their awareness, mother health condition and having any savings have a significant association with adherence $(\mathrm{P}<0.005)$. Conclusion: Adherence of the cerebral palsy child with physiotherapy appointment is out most important for better management. In this study, it is suggested that the quality of life of the CP child is significantly changed by physiotherapy as well as rehabilitation.
\end{abstract}

Keywords: Cerebral Palsy, Physiotherapy, Caregivers, Adherence, Rehabilitation

\section{Introduction}

Cerebral palsy is a non-progressive irreversible lesion either single or multiple areas of the immature brain due to a developmental abnormality of brain or injury of the brain during labor, at the time of birth or during delivery [1]. It is the most commonly occurring neurodevelopment disorder beginning in the early stage of the neonatal period and persists for while lifelong [2]. The prevalence of CP is much higher in preterm infants than in full terms infants [3]. Worldwide, the prevalence of cerebral palsy is $2.5 \%$ per one thousand live births [4]. Cerebral palsy is 5 to 10 -fold more prevailed in lower economic countries in the glove [5].

Bangladesh is a developing country and the prevalence of Cerebral palsy in Bangladesh was 3.7 per thousand of the children in a live birth [6]. Another study conducted on the prevalence of childhood disabilities and cerebral palsy in the community and recommended that the prevalence of cerebral palsy in Bangladesh was 6.1/1000 in a live birth [7].

The prevalence of disability due to cerebral palsy in a population of children ages 2-9 years from both urban and rural populations was estimated to be 70/1,000 for all grades of severity and 22/1,000 for serious disability in Bangladesh [8]. 
In the light of international initiatives and quality of service and the right and protection of persons of disabilities declared by the UNCRPD, Bangladesh government form Neuro-developmental Disability protection act 2013, the national disability development foundation was formed in 2009 and it is responsible for the ministry of social welfare. There are 103 Protibondhi Seba-O-Sahajjo Kendro (PSOSK) are operating by this foundation. The main aim of those centers is to provide free disability detection survey activities in all districts and provide free medical and therapy services to all persons with disabilities and persons at the risk of disability to ensure healthy living. In the fiscal year of 20172018, nearly 40 lacks and four thousand medical and therapy services and about 34 thousand assistive devices were provided through 103 PSOSK.

As cerebral palsy cannot be fully cured, different therapeutic intervention with a multidisciplinary team approach is used for secondary impairment prevention and ensuring the natural developmental milestone of the cerebral palsy child [9]. Physiotherapy is more frequently used for functional improvement of the cerebral palsy child [10]. Mothers of children with cerebral palsy are usually the primary caregivers of their children, [11]. Typically, in rural and undeveloped areas, these caregivers have had no or limited access to skills and training [12]. Consequently, it is out most important to recognize how parents/caregivers of the children with cerebral palsy manage their children's physiotherapy services and the potential barriers they encounter during the use of the services. Hence knowledge of those factors that affect adherence to physiotherapy appointments among the children with CP has an important association for ongoing efforts directed at proper rehabilitation of those children [13]. So, the aim of this study is to find out the factors affecting adherence to physiotherapy appointments of children with cerebral palsy in Bangladesh.

\section{Materials and Methods}

A cross-sectional study was carried out at protibondhi seba-o-sahajjo kendro (PSOSK) from the fourteen (14) different districts and Upazila in Bangladesh. 225 participants were assigned randomly. The researcher took data from the principal caregiver's randomly who came at PSOSK. The Inclusion criteria of the study was diagnosed cerebral palsy child's who already registered for physiotherapy treatment at PSOSK. Age is between 1-10 years and who received physiotherapy intervention at least three months.

Prior to collect data the purpose of the study was explain and written consent were taken. Data were collected through a self-developed questionnaire consisting of closed structured question through face-to-face interview. Prior to data collection expert opinion were taken to validate the questionnaire. Data was collected within a short period of time and the total procedure were completed at 30 days.

Adherence is estimated by considering the number of the attendance of prescribed appointments divided by the total session he or she received treatment (from the first appointment) multiply by one hundred i.e., Adherence $=$ Session of received treatment/ prescribed appointments $X 100$. Where $\geq 70 \%$ score is considered at adherence, while $<70 \%$ considered to be non-adherence.

\section{Result}

There are 225 children with cerebral palsy enrolled in this study. Among them $44 \%$ is quadriplegic $\mathrm{CP}, 26.7 \%$ is hemiplegic CP. Rests of percentage $(29.3 \%)$ were suffering either Monoplegic or paraplegic type of cerebral palsy.

Table 1. Characteristics of the study participants $(n=225)$.

\begin{tabular}{ll}
\hline Age: mean (SD), month & $48.6(30.55)$ \\
Sex: boy, n (\%) & $114(54.8 \%)$ \\
Schooling (Age>60months) N=63 & \\
No: $\mathrm{n}(\%)$ & $41(65.08)$ \\
Other disease: Yes, n (\%) & $62(27.6)$ \\
Other disability: Yes, n (\%) & $102(45.3)$ \\
Assistive device: Yes, n (\%) & $103(45.8)$ \\
Dependent on others for ADL & \\
Yes, $\mathrm{n}(\%)$ & $211(93.8)$ \\
Principal caregiver: Mother, $(\%)$ & $(91.6)$ \\
Rate of Adherence, $\mathrm{n}(\%)$ & $76(33.8)$ \\
Non-Adhere, $\mathrm{n}(\%)$ & $149(66.2)$ \\
\hline
\end{tabular}

\subsection{Caregiver's Awareness and Spend Time at Home for Exercises}

Among the caregiver $44.4 \%$ of them had no knowledge/awareness about Physiotherapy, 38.70\% had minimal awareness about treatment and $14.20 \%$ was known what exercise was performed for physiotherapy treatment for their child and only $2.7 \%$ of caregiver had clear image about physiotherapy and they are very optimistic about the health of their child. $51.1 \%$ caregiver did not spend time at home for exercising their $\mathrm{CP}$ child. The mean times were $35.15 \pm 33.90$ minutes.

\subsection{Traveling Time, Waiting Time and Cost Required for Receiving Services}

Table 2. Socio-cultural information of the participants.

\begin{tabular}{|c|c|c|c|c|}
\hline Variables & Frequency & $\%$ & Frequency & $\%$ \\
\hline \multicolumn{3}{|c|}{ Father attitude towards CP child } & \multicolumn{2}{|c|}{ Neighborhood view with $\mathrm{CP}$} \\
\hline Strong Positive & 59 & 26.3 & 29 & 12.9 \\
\hline Positive & 133 & 59.4 & 142 & 63.1 \\
\hline Negative & 03 & 1.3 & 09 & 4.0 \\
\hline Strongly negative & 29 & 12.9 & 45 & 20 \\
\hline \multicolumn{3}{|c|}{ Family member help to take care } & \multicolumn{2}{|c|}{ Other child meet \& play } \\
\hline Yes & 49 & 73.1 & 152 & 67.6 \\
\hline No & 18 & 26.9 & 73 & 32.4 \\
\hline \multicolumn{3}{|c|}{$\begin{array}{l}\text { Family member interrupts for receiving PT } \\
\text { treatment }\end{array}$} & \multicolumn{2}{|c|}{$\begin{array}{l}\text { Who interrupt for receiving } \\
\text { PT treatment }\end{array}$} \\
\hline Yes & 18 & 8.0 & \multicolumn{2}{|c|}{ Father $=11(61.1)$} \\
\hline No & 207 & 92.0 & \multicolumn{2}{|c|}{$\mathrm{GM}+\mathrm{GF}=5(27.9)$} \\
\hline
\end{tabular}

Almost every participant has to wait for some time to get treatment, maximum waiting time was 180 minutes and mean waiting time was $28.63 \pm 24.19$ minutes. Minimal 10 minutes and maximum 210 minutes were required to reach the center. 
Minimum travelling cost was 10 and maximum was 500 takas, the mean cost was $87.98 \pm 78.95$ taka.

Here, GM-grandmother, GF-grandfather

There are (Table 2) 67 number of families were combined among them $26.9 \%$ cases others family member didn't help to take care the disable child. $67.6 \%$ of other child of the family regularly meet and play with the disable child and $32.4 \%$ didn't play and meet with the CP child. Only $8 \%$ of family members interrupted for receiving Physiotherapy treatment among them $61.1 \%$ interruption was provided by father and $16.7 \%$ provided by grandmother.

Table 3. Characteristic of CP children and adherence.

\begin{tabular}{|c|c|c|c|c|c|}
\hline \multirow{2}{*}{ Variables } & \multicolumn{2}{|l|}{ ADHERENCE } & \multirow{2}{*}{ df } & \multirow{2}{*}{$\mathbf{x 2}$} & \multirow{2}{*}{ P-Value } \\
\hline & Adhere N=76 (33.8\%) & Non-adhere $\mathrm{N}=149(66.2 \%)$ & & & \\
\hline \multicolumn{6}{|l|}{ Siblings } \\
\hline No sibling & $42(18.7)$ & $52(23.1)$ & 1 & 8.580 & $.003 * *$ \\
\hline Siblings & $34(15.1)$ & $97(43.1)$ & & & \\
\hline \multicolumn{6}{|c|}{ Doctor consultancy } \\
\hline Yes & $67(29.8)$ & $107(47.6)$ & 1 & 7.671 & $.006 * *$ \\
\hline No & $09(4.0)$ & $42(18.7)$ & & & \\
\hline \multicolumn{6}{|c|}{ Mother's education } \\
\hline Below SSC & $39(17.3)$ & $111(49.3)$ & 1 & 12.17 & $.000 * *$ \\
\hline Above SSC & $37(16.4)$ & $38(16.9)$ & & & \\
\hline \multicolumn{6}{|l|}{ Mother illness } \\
\hline Yes & $18(8.0)$ & $18(8.0)$ & 1 & 5.042 & $.025 *$ \\
\hline No & $58(25.8)$ & $131(58.2)$ & & & \\
\hline \multicolumn{6}{|c|}{ Father Education (One father was left due to dead) } \\
\hline Above SSC & $40(17.8)$ & $44(19.6)$ & & & \\
\hline \multicolumn{6}{|l|}{ Family members } \\
\hline Three & $28(12.4)$ & $36(16.0)$ & 1 & 3.976 & $.046 *$ \\
\hline$>$ Three & $48(21.3)$ & $113(50.2)$ & & & \\
\hline \multicolumn{6}{|l|}{ Family savings } \\
\hline Yes & $30(13.3)$ & $30(13.3)$ & 1 & 9.626 & $.002 * *$ \\
\hline No & $46(20.4)$ & $119(52.9)$ & & & \\
\hline \multicolumn{6}{|c|}{ Expenditure for physiotherapy treatment (Taka) } \\
\hline Upto1000 taka & $50(22.2)$ & $124(55.1)$ & 1 & 8.725 & $.003 * *$ \\
\hline Above 1000taka & $26(11.6)$ & $25(11.1)$ & & & \\
\hline
\end{tabular}

$(*=$ Level of significant, $* \mathrm{P}<.05)$

In this study (Table 3) $58.2 \%$ of CP child had siblings, among them $43.1 \%$ showed non-adherence. $77.4 \%$ of $\mathrm{CP}$ child consult with doctor among them $47.6 \%$ showed nonadherence with treatment, on the other hand $22.7 \%$ of $\mathrm{CP}$ child did not consult with doctors and among these percentage comparatively higher $18.7 \%$ of participant showed non-adherence with treatment.

\subsection{Parents and Adherence}

Mother's illness has also significant relation with adherence with Physiotherapy treatment (Table 3), 73.3\% of families had no savings that indicate they lived in low economic condition and the rate of non-adherence was $52.9 \%$.

Table 4. Residence, Transportation and adherence.

\begin{tabular}{|c|c|c|c|c|c|}
\hline \multirow{2}{*}{ Variables } & \multicolumn{2}{|l|}{ ADHERENCE } & \multirow{2}{*}{ df } & \multirow{2}{*}{$\mathbf{x} 2$} & \multirow{2}{*}{ P-Value } \\
\hline & Adhere $\mathrm{N}=76(33.8 \%)$ & Non-adhere $\mathrm{N}=149(66.2 \%)$ & & & \\
\hline \multicolumn{6}{|c|}{ Location of the residence } \\
\hline Village & $45(20.0)$ & $116(51.6)$ & & & \\
\hline Thana & $09(4.0)$ & $15(6.7)$ & 2 & 10.647 & $.005 * *$ \\
\hline District & $22(9.8)$ & $18(8.0)$ & & & \\
\hline \multicolumn{6}{|c|}{ Distance from PSOSK to residence of the participants } \\
\hline Above10000meters & $19(8.4)$ & $70(31.1)$ & & & \\
\hline \multicolumn{6}{|c|}{ Time required for reaching PSOSK } \\
\hline Up to30 $\mathrm{min}$ & $45(20.0)$ & $59(26.2)$ & 1 & 7.789 & $.005 * *$ \\
\hline Above $30 \mathrm{~min}$ & $31(13.8)$ & $90(40.0)$ & & & \\
\hline
\end{tabular}

(*=Level of significant, $* \mathrm{P}<.05)$

As nearly two third of the participants lived in village (Table 4), $60.4 \%$ of participants required travel up to $10 \mathrm{Km}$, among them $35.1 \%$ showed non-adherence, $46.2 \%$ of participants required up to 30 minutes of traveling to reach 
the PSOSK and among them $26.2 \%$ was non-adherence.

Table 5. Socio-cultural characteristics of the participants and adherence.

\begin{tabular}{|c|c|c|c|c|c|}
\hline \multirow{2}{*}{ Variables } & \multicolumn{2}{|l|}{ ADHERENCE } & \multirow{2}{*}{ df } & \multirow{2}{*}{$\mathbf{x} 2$} & \multirow{2}{*}{ P-Value } \\
\hline & Adhere N=76 (33.8\%) & Non-adhere $N=149(66.2 \%)$ & & & \\
\hline \multicolumn{6}{|c|}{ Father's attitude towards CP child } \\
\hline Positive & $73(32.4)$ & $119(52.9)$ & 1 & 10.040 & $.002 * *$ \\
\hline Negative & $03(1.3)$ & $29(12.9)$ & & & \\
\hline \multicolumn{6}{|c|}{ Neighborhood view to the $\mathrm{CP}$ child } \\
\hline Positive & $66(29.3)$ & $106(47.1)$ & 1 & 6.890 & $.009 * *$ \\
\hline Negative & $10(4.4)$ & $43(19.1)$ & & & \\
\hline \multicolumn{6}{|c|}{ Caregiver level of awareness about Physiotherapy } \\
\hline No knowledge & $22(9.8)$ & $78(34.7)$ & 1 & 11.163 & $.001 * *$ \\
\hline Knowledgeable & $54(24.0)$ & $71(31.6)$ & & & \\
\hline \multicolumn{6}{|c|}{ Caregiver spent time at home exercise } \\
\hline Yes & $49(21.8)$ & $61(27.1)$ & 1 & 11.155 & $.001 * *$ \\
\hline No & $27(12.0)$ & $88(39.1)$ & & & \\
\hline \multicolumn{6}{|c|}{ characteristics of services provided by the institute and adherence } \\
\hline \multicolumn{6}{|c|}{ Therapy providing times } \\
\hline$<30$ minutes & $35(15.6)$ & $105(46.6)$ & 1 & 12.765 & $.000 * *$ \\
\hline$>30$ minutes & $41(18.2)$ & $44(19.6)$ & & & \\
\hline \multicolumn{6}{|c|}{ Providing therapy regularly as per prescription } \\
\hline Yes & $66(29.3)$ & $108(48.0)$ & 1 & 5.920 & $.015^{*}$ \\
\hline No & $10(4.4)$ & $41(18.2)$ & & & \\
\hline \multicolumn{6}{|c|}{ Physiotherapist's attitude towards the caregiver of $\mathrm{CP}$ child } \\
\hline Positive & $74(32,9)$ & $133(59.1)$ & 1 & 4.494 & $.034 *$ \\
\hline Negative & $02(0.8)$ & $16(7.1)$ & & & \\
\hline \multicolumn{6}{|c|}{ Condition of the $\mathrm{CP}$ child changed after receiving treatment } \\
\hline Yes & $71(31.6)$ & $79(35.1)$ & 1 & 36.967 & $.000 * * *$ \\
\hline No & $05(2.2)$ & $70(31.1)$ & & & \\
\hline
\end{tabular}

$(*=$ Level of significant, $* \mathrm{P}<.05)$

Study result (Table 5) showed that among the fathers of 224 CP child 192 fathers showed positive attitude and their adherence rate was high. On the other hand, 32 father showed negative attitude, among them $29 \mathrm{CP}$ child showed nonadherence. Above table also showed that $23.5 \%$ of neighbor showed negative view towards the CP child among them $19.1 \%$ was non-adherence.

\subsection{Characteristic of Caregivers and Adherence}

There are (Table 5) $44.5 \%$ of caregiver had no knowledge about physiotherapy among them $34.7 \%$ were non-adhered with treatment and $55.6 \%$ had some knowledge about what treatment was provided to their child, among them $24 \%$ adhered with treatment. $51.1 \%$ of participant did not spent time at home for exercise, among them $39.1 \%$ were nonadhered with treatment and $48.9 \%$ of participants spent time at home for exercise, also among them $27.1 \%$ were nonadhered with treatment.

\subsection{Characteristics of Services Provided by the Institute and Adherence}

Result (Table 5) shown that $62.2 \%$ of participants received treatment less than 30 minutes among them maximum $46.5 \%$ were non-adhered with treatment on the other hand $77.3 \%$ of cases therapy was provided regularly, among them $48 \%$ were non-adhered and $22.6 \%$ of cases therapy was provided irregularly, among them $18.2 \%$ were non-adhered with treatment. There is a significant relationship with the physiotherapist attitude towards the caregiver and adherence and also how much the conditions changed after receiving the physiotherapy, $33.3 \%$ of cases the condition of the CP child was unchanged after receiving the treatment and among them $31.1 \%$ showed non-adherence.

\section{Discussion}

The result of this study shows that the mean age of the CP child was $49.90 \pm 29.50$ months, which was comparable with a study in India (2018) in about the clinical profile of cerebral palsy in which, overall mean age was 48.84 months. The maximum number $56(24.9 \%)$ of CP child presentation were in the age group of 12-24 months in both sex and this study $71.9 \%$ of child age within five years, this result was similar with the study of [14] Makwana.

This study showed that the number of siblings had a significant relationship with adherence $(\mathrm{P}<0.003), 58.2 \%$ of CP children had siblings, among them $43.1 \%$ showed nonadherence. Those families have more than one child, traveling to and from for therapy appointment as per the schedule and their need for childcare assistance, sometimes required schooling the aged siblings that become great barriers for this caregiver for maintaining adherence to 
treatment [1]. Among the $225 \mathrm{CP}$ children, only $76(33.8 \%)$ maintain adherence and149 (66.2\%) was non-adherence. Similarly, a classical study [13] shows that $28(46.7 \%)$ of the participant was adherence and $32(53.3 \%)$ was nonadherence. According to the WHO, there are five factors influencing adherence thus include social and economic factors, health system-related factors, therapy-related factors, disease-related factors, and patient-related factors [15].

Majority of the principal caregivers are the biological mother $(91.6 \%)$ of the CP child and their non-adherence rate was high $(60.0 \%)$. In this study, three mothers were divorced and one mother was widowed, all of them were non-adhered with treatment, similar findings were observed in a study where the high rate of non-adherence was recorded among the divorced caregiver [13].

Result also shows that non-adherence rates were more than two times greater than adherence in parent's education level below SSC, on the other hand parents whose education level were above SSC their rate of adherence nearly $50 \%$ and had a strong relationship with the adherence $(\mathrm{P}<0.05)$. This result is similar to the study conducted in the Kano metropolis who found that the education level of caregivers has a strong relationship with adherence to PT appointment [13]. Although PSOSK provided physiotherapy services for the $\mathrm{CP}$ children free of cost rural people required high traveling costs due to long-distance, so it becomes a major barrier for a poor family in Bangladesh. This constraint also found in India the researcher found that transportation to the $\mathrm{CP}$ child to physiotherapy center involves considerable expenses for a poor family and thus became major barriers even though services provided free of the coast [16].

Service duration and physiotherapist attitude towards the patient has a significant relationship with adherence, Caregivers be satisfied and confident on their therapist resulting in they made more adhere to treatment. Literature showed that a longer duration of treatment period might influence the adherence of chronic ill patients with treatment for the prolog period [17]. There was a significant association between the home exercise program and adherence (P-value 0.001). Non-adherence to home exercise programs is documented as one of the factors affecting treatment outcomes [18].

\section{Conclusion and Recommendations}

Considering the results of this study, and the difficulties parents experienced in adherence to all treatment appointment at the PSOSK. There is a need to decentralize services from district to Union health centers in the community that are accessible to most patients/caregivers. This can be implemented through outreach clinics in communities that are located far away from the district. This strategy would shorten the distance for parents, increase the accessibility of these services to the very poor families those are unable to meet transportation costs and would be an effective strategy of taking services nearer to the people.

\section{References}

[1] Cada, E. A., \& O'Shea, R. K. (2008). Identifying barriers to occupational and physical therapy services for children with cerebral palsy. Journal of pediatric rehabilitation medicine, 1 (2), 127-135.

[2] Sharma, R., \& Sinha, G. A. (2016). Impact of physiotherapy service utilization on physical and functional status of children with cerebral palsy in Jalandhar, Punjab, India. Journal of Health and Research, 3 (3), 173-180.

[3] Vincer, M. J., Allen, A. C., Joseph, K. S., Stinson, D. A., Scott, H., \& Wood, E. (2006). Increasing prevalence of cerebral palsy among very preterm infants: a population-based study. Pediatrics, 118 (6), 1621-1626.

[4] Tollanes, M. C., Wilcox, A. J., Lie, R. T., \& Moster, D. (2014). Familial risk of cerebral palsy: population-based cohort study. British medical journal, 349, 4294.

[5] Cruz, M., Jenkins, R., \& Silberberg, D. (2006). The burden of brain disorders. Science, 312 (5770), 53-53.

[6] Murthy, G. V., Mactaggart, I., Mohammad, M., Islam, J., Noe, C., Khan, A. I., \& Foster, A. (2014). Assessing the prevalence of sensory and motor impairments in childhood in Bangladesh using key informants. Archives of disease in childhood, 99 (12), 1103-1108.

[7] Tabib, S. M. S. B. (2009). Prevalence of childhood disabilities and cerebral palsy in the community.

[8] Mubarak, R., Khan, N. Z., Munin, S., Zaman, S. S., \& Conachie, H. M. (2000). Predictors of stress in Mothers of children With Cerebral Palsy in Bangladesh. Society of Pediatric Psychology, 25 (6), 427-433.

[9] Sharan, D. (2005). Recent advances in the management of cerebral palsy. Indian Journal of Pediatrics, 72, 969-73.

[10] Patel, D. R. (2005). Therapeutic interventions in cerebral palsy. The Indian Journal of Pediatrics, 72 (11), 979-983.

[11] National Bureau of Statistics. 2011, Nigeria.

[12] Servaes, J., Galasso, E., Umapathi, N., Salem, R. M., Bernstein, J., Sullivan, T. M.,... \& Witte, K. (2016). Community mobilization through women's groups to improve the health of mothers and babies. Good practice guide. International Communication Gazette, 69 (6), 483507.

[13] Usman, M. Y., Abdulmanaf, A., Abba, M. A., \& Kani, M. Z. (2017). Factors affecting adherence to physiotherapy appointments for caregivers of children with cerebral palsy in Kano metropolis. Arch Physiotherapy Glob Res, 21 (2), 13-19.

[14] Makwana, M.., Mourya, H. K., Saroj Mourya, S., Gupta, B. D., Bhati, R. L. \& Garg, Y. (2017). A clinicoepidemiological study of cerebral palsy in western Rajasthan. International Journal of Contemporary Pediatrics, 4 (4), 1146-1152.

[15] World Health Organization. (2003). Adherence to long-term therapies: evidence for action. from: http://www.who.int/chp/ knowledge/ publications/ adherence_report/en/. Retrieved from 04 May, 2019. 
Md. Rafiqul Islam et al.: Factors Influencing the Utilization of Physiotherapy Services Among the Children with Cerebral Palsy at Protibondhi Seba-O-Sahajjo Kendro in Bangladesh

[16] Sinha, A. G., \& Sharma, R. (2017). Factors influencing utilization of physiotherapy service among children with cerebral palsy in Jalandhar district of Punjab. Journal of neurosciences in rural practice, 8 (2), 209.

[17] Dhanireddy, K. K., Maniscalco, J., \& Kirk, A. D. (2005). Is tolerance induction the answer to adolescent non-adherence? Pediatric transplantation, 9 (3), 357-363.
[18] Rone-Adams, S. A., Stern, D. F., \& Walker, V. (2004). Stress and compliance with a home exercise program among caregivers of children with disabilities. Pediatric physical therapy, 16 (3), 140-148. 